\title{
Importance of fasting blood glucose goals in the management of type 2 diabetes mellitus: a review of the literature and a critical appraisal
}

\begin{abstract}
Prandial insulin has been essential for the improved management of the type 1 diabetic patient. Interestingly, many studies have evaluated the addition of prandial insulin to the type 2 diabetic patients with improved control. The greatest drop in A1c with the use of various type of prandial insulins have resulted in the decrease of $1.3 \%$ in the A 1c measurement. Interestingly, none of the published trials with goal of fasting blood glucose $(\mathrm{FBG})$ have ever obtained the goal A1c. Since a drop in FBG of $28.5 \mathrm{mg} / \mathrm{dl}$ is equal to a $1 \%$ drop in $\mathrm{A} 1 \mathrm{c}$, a simple approach to obtain a target A1c would be to focus on the FBG (per ADA: Average Blood Glucose =A1c (\%) x $28.7-46.7 \mathrm{mg} / \mathrm{d})$. However, average blood glucose requires multiple measurements and may be less accurate then using just a FBG. Since prandial insulin clinical trials have only demonstrated a drop in A1c by $0.3-1.3 \%$ the use of only a FBG to help patients get to goal may be easier to teach and to obtain and it might save time and money. Our hypothesis is that if patient obtain a FBG $<100 \mathrm{mg} / \mathrm{dl}$ of a few month period, then $70 \%$ will be at an $\mathrm{A} 1 \mathrm{c}$ goal $<7.0 \%$. After a few months of good fasting glucose control the provider can use this equation $(\mathrm{FBG}+80) / 30$ to estimate $\mathrm{A} 1 \mathrm{c}$. For example, a FBG of $130 \mathrm{mg} / \mathrm{dl}$ would be $(130+80) / 30=7.0 \%$; or a FBG of 190 would be $(190+80) / 30=$ eA 1 c $9 \%$ (estimate of A1c). While type 1 diabetes is a very complex daily glucose pattern, the approach to type 2 diabetics on insulin could become simplified.
\end{abstract}

Volume 5 Issue 4 - 2018

\author{
Chandler J Tayek, Lavanya Cherukuri, Sajad \\ Hamal, John A Tayek \\ Department of Internal Medicine, Los Angeles Bio-Medical
} Research Institute, USA

Correspondence: John A Tayek, Department of Internal Medicine, Los Angeles Bio-Medical Research Institute, $1000 \mathrm{~W}$. Carson Street, Box 428, Torrance, CA 90509, USA, Tel 310222 1237, Fax 310320 8459, Email jtayek@dhs.lacounty.gov

Received: March 07, 2018 | Published: July 20, 2018
Abbreviations: FBG, fasting blood glucose; ADA, average blood glucose, ACP, autologous conditioned plasma; A1C, hemoglobin A1c; AACE, American association of clinical endocrinologists

\section{Introduction}

Nearly all of the reviewed randomized clinical trials (24 of 25) have demonstrated that after entry into a clinical trial, the \% A1c drops below $7.9 \% \%^{1-25}$ with the use of just basal insulin. Prandial insulin's have been used to treat type 1 diabetics and have become a common treatment for type 2 diabetics who are not at goal. Type 2 diabetic patients are in a prandial state for few hours with each meal. In comparison, the type 1 diabetic patients have larger and longer durations of glucose excursions after a mean (meal???) which can account for $50 \%$ of the A1c value. The exact contribution of prandial glucose excursion in type 2 diabetic patients may be altering glucose levels to a smaller role base on the benefits of basal insulin suppressing hepatic and renal glucose production, dietary changes that have many patients eating less carbohydrate and the easy of administering basal insulin as a single once daily injection. For example, basal insulin administration has demonstrated that $68 \%$ of patients can get to an A1c of $7.0 \%$ or lower after 6 months of just basal treatment. ${ }^{2}$ With the recent change in the A1c goal to be that of $<8.0 \%$, the percentage of type 2 diabetic patient getting to goal may be approaching $90 \%$ with just basal insulin alone. Data from the 30 clinical trials were reviewed for the percentage of patients with an A1c goal of $\leq 7.0 \%$. Our primary hypothesis is that if providers obtain an average FBG of $90 \mathrm{mg} / \mathrm{dl}$, then approximately $70 \%$ will be at an ADA A1c goal $\leq 7.0 \%$. Based on the newer ACP goal of an A1c $<8.0 \%$, then approximately $90 \%$ will be at goal with if the FBG of $90 \mathrm{mg} / \mathrm{dl}$ is obtained.

\section{Methods}

Pubmed was searched as of June 2018 for clinical trials that have tested basal insulin analogue regimen in previously insulin naïve patients to evaluate the physiological effects and clinical outcomes using prandial vs basal alone insulin. Twenty five clinical trials using basal insulin were included in the final analysis. Twenty four of these clinical trials looked single basal insulin injection versus mixed dual insulin multiple injections in type 2 diabetic patients to identify if one regimen obtains a greater reduction in Alc values. All papers were included if the authors reported the percentage of diabetics at or below $7.0 \% \%^{2-18,21-25}$ or if this data was extractable from the published data. ${ }^{19,20}$ None of the trials reported \% of patients at ACP goal A1c of $<8.0 \%$ but data was abstracted from the reported data. ${ }^{4}$

All the data reported percentage of patients at Data was presented as mean \pm SEM. Significance was determined by ANOVA with significance defined as a $\mathrm{p}<0.05$. Linear regression was done by least squares and best equation determined that would permit FBG to predict \% of patients at A1c goal. The regression equation demonstrated the relationship between the obtain FBG in each arm of the clinical trials to the percentage of patients at the ADA Alc goal of $\leq 7.0 \%$. Interpretation of the relationship between FBG and the percentage at goal will developed and estimates of those at the new ACP goal of $8 \%$ was obtained (21).

\section{Results}

Data was extracted from 26 clinical trials or reviews and entered into an Excel file for evaluation of the relationship between FBG and $\%$ of diabetics at goal as defined as by ADA and AACE of an A1c $<7.0 \%$ and by ACP of an A1c $<8.0 \%$. The majority of these trials 
were funded by manufactures of prandial insulin and the authors goal were to evaluate the benefit of adding prandial insulin to basal insulin to improve diabetic control. Eight clinical trials evaluate the addition of prandial insulin to basal insulin alone. ${ }^{2-6}$ The improvement in A1c ranged from 0.1 to $0.8 \%$, and a larger proportion of patients obtained a goal A1c. However, there was a greater significant increase in the rate of hypoglycemia in most trials. In these eight clinical trial, the use of multiple injections of insulin resulted in a mean improvement in A1c of $0.36 \pm 0.21 \%($ mean $\pm \mathrm{SD}, \mathrm{NS})$. While any improvement in A1c is likely better care for the patient, this may be obtained with a more focused approach of obtaining a low FBG goal now with the use of basal insulin and may reduce the incidence of hypoglycemia. This investigator believes that there may be an alternative explanation as described below:

Most trials were designed by companies funding rapid acting insulin with a goal to show superior benefits with rapid onset insulin as compared to standards of medical care. This interest could have produced a bias based on the fact that most studies increased rapid insulin treatment based on A1c measurements and not or fasting and post-prandial blood glucose concentration. For example, FBG goals were set to be less than 140,126 or $120 \mathrm{mg} / \mathrm{dl}$ respectively in 4 of the 8 trials..$^{4-7}$ Since a change of $1 \%$ in the A1c measurement represents $28.5 \mathrm{mg} / \mathrm{dl}$ change in the average blood glucose, a drop in FBG of $28.5 \mathrm{mg} / \mathrm{dl}$ should represent a $1 \%$ drop in A $1 \mathrm{c}$ (See explanation below). Having a goal of $<120,<126$ or $<144$ respectively in 4 of the trials resulted in the highest FBG, $(128 \mathrm{mg} / \mathrm{dl}, 126 \mathrm{mg} / \mathrm{dl}, 124 \mathrm{mg} / \mathrm{dl}, 128 \mathrm{mg} /$ dl). (It is interesting that the goal for FBG was never achieved in these trials). If patients were able to obtain a FBG from $128 \mathrm{mg} / \mathrm{dl}$ down to FBG $100 \mathrm{mg} / \mathrm{dl}$, then the FBG would have dropped $28 \mathrm{mg} / \mathrm{dl}$ which would have resulted in an additional drop in A1c by approximately $1 \%(\mathrm{~A} 1 \mathrm{c}=28.5 \mathrm{mg} / \mathrm{dl})$ :

i. In four trials that set the strict goal of a FBG $<110$ or lower, none of the trials obtained the goal FBG $(114,117,122 \mathrm{mg} / \mathrm{dl}$, not-reported) respectively. Again, based on the fact that an A1c represent an average blood glucose (or fasting blood glucose) change of $28.5 \mathrm{mg} / \mathrm{dl}$, obtaining a more strict goal of $90 \mathrm{mg} / \mathrm{dl}$ would have reduced the A1c by 1.0 additional percent.

ii. Most importantly, when FBG is reduced below $110 \mathrm{~g} / \mathrm{dl}$, the patient's endogenous first phase insulin response improves in most type 2 diabetic patients given intravenous glucose. ${ }^{11}$ Therefore; the diabetic patient may be able to better respond to acute glucose increases with endogenous insulin secretion. Since the majority of insulin secretion is trapped in the liver, the return of endogenous insulin secretion will blunt the post-prandial glucose rise as the insulin can effectively suppress hepatic glucose production.

iii. Approximately $70 \%$ of the endogenous insulin release is trapped in the liver which exerts it effect to suppress endogenous glucose production. Interestingly, at a FBS of $110 \mathrm{mg} / \mathrm{dl}$ the ability of the beta cell to make additional insulin in the diabetic is impaired when compared to a fasting blood glucose concentration under $110 \mathrm{mg} / \mathrm{dl}$. Unappreciated by many clinicians, endogenous insulin secretion is restricted when FBG is above $110 \mathrm{mg} / \mathrm{dl}$. This is one of the reasons why AACE recommends that FBG be below $110 \mathrm{mg} / \mathrm{dl}$ (See AACE guidelines 2018) in contrast the ADA that says the FBG should be between 70 and 130. This latter range is approximately $2.1 \%$ A $1 \mathrm{c}$ delta $(60 / 28.5=2.1)$.

iv. In a study of 785 diabetic patients, basal insulin was given for 14-weeks before being randomized to three different rapid insulin arms. After this 14 -week run-in period, $47 \%$ of the patients on basal insulin alone were not randomized to any of the rapid treatment arms because they were at A1c goal $(\leq 7 \%$ of lower; Ref 12). Extrapolation of the percentage at goal with FBG 130 was approximately $90 \%$.

In an attempt to validate the approach, the results from the 26 publications resulted in 54 data points including both FBG and \% of patients with A1c $\leq 7.0 \%$. Each data point was the mean for the treatment and the control arm of the study. The data demonstrates a significant regression correlation (Figure 1). Interestingly, the equation is simple to use: $(174-107 \times \mathrm{FBG}=$ Percentage of population with A $1 \mathrm{c} \leq 7.0 \%$ ). For example, FGB of $90 \mathrm{mg} / \mathrm{dl}$ would be obtained and the formula would estimate that $(174-1.07 \times 90) 77.7 \%$ would be at goal A1c $\leq 7.0 \%$. Based on Table 1 , the $28 \mathrm{mg} / \mathrm{dl}$ increase blood glucose would translate into an approximate A1c $<8.0 \%$ which is the new ACP guidelines to diabetics to be at goal. Therefore, approximately $90 \%$ of patients with a FBG of $120 \mathrm{mg} / \mathrm{dl}$ should be at a goal A1c of $7.9 \%$ or lower.

\section{Discussion}

The ADA goal for FBG concentrations are the same for patients with both type 1 and type 2 diabetes mellitus. The goal range is between 70 and $130 \mathrm{mg} / \mathrm{dl}$. This $60 \mathrm{mg} / \mathrm{dl}$ range between $70-130 \mathrm{mg} /$ $\mathrm{dl}$ accounts for about a $2.1 \%$ change in A1c for most type 2 diabetics. For the type 1 diabetic, the wide range may not account for $2 \%$ in A1c control because the glucose variability is quite high for type 1 patients when compared to type 2 diabetic patient. While having a target FBG of $90 \mathrm{mg} / \mathrm{dl}$ may be considered too tight a goal for the DM-1, but this may be a safe way to approach patient with DM-2. We know hypoglycemia is a common reason for ER visits. The majority of these visits are likely due to prandial insulin (when not eating) or sulfonylurea mediations. In comparison, both AACE and Canadian Medical Association have a FBG range more consistent with the physiological process of insulin secretion (as discussed below) between 110 and $90 \mathrm{mg} / \mathrm{dl}$.

Beta cell response to intravenous glucose is absent at a fasting blood glucose of $115 \mathrm{mg} / \mathrm{dl}$ to $140 \mathrm{mg} / \mathrm{dl} .{ }^{11}$ At FBG of 100 to $114 \mathrm{mg} / \mathrm{dl}$, the insulin response to glucose is minimal. In comparison, at a FBG of 79 to $89 \mathrm{mg} / \mathrm{dl}$ and at a FBG between 90 and $99 \mathrm{mg} / \mathrm{dl}$, the first phase insulin response is robust. ${ }^{11}$ First phase insulin response is essential to regulate hepatic glucose production rate which is mostly responsible for FBG concentration. Adding adequate basal insulin suppressed hepatic glucose production rates to such a level as the FBG decreases.

First phase insulin response occurs when fasting glucose concentrations are below $111 \mathrm{mg} / \mathrm{dl}$. Unfortunately, none of the eight clinical trials obtained a FBG $<110 \mathrm{mg} / \mathrm{dl}$. A FBG goal was set for all 26 clinical trials, none of the studies obtained the goal mean FBG. In an additional study similar to the Davidson study, ${ }^{11}$ if you treat with basal insulin (glargine) for 6 months with an average FBG of 120mg/ $\mathrm{dl}$, then $46 \%$ of your patients will have an $\mathrm{A} 1 \mathrm{c} \leq 7.0 \%{ }^{14}$ In an attempt to help refocus the importance of FBG and A1c, Table 1 list to goal FBG to obtain an A1c concentration. Instead of using the $28.5 \mathrm{mg} / \mathrm{dl}$ per A1c, Table 1 has been simplified for every $30 \mathrm{mg} / \mathrm{dl}$ is $1 \% \mathrm{~A} 1 \mathrm{c}$. (ADA table is similar for mean BG if you add approximately $30 \mathrm{mg}$ to Table 1). Obtaining a FBG of 120 for a 6-month period resulted in a mean A1c of $6.7 \%$ in a large clinical trial. ${ }^{13}$ This number is exactly what would be expected in type 2 diabetic patients where 18 hours of the 24-hour day reflects fasting state where fasting blood glucose 
accounts for $80 \%$ of the glucose area under the curve. In comparison, after 12 weeks of therapy the average fasting blood glucose of $148 \mathrm{mg} /$ $\mathrm{dl}$ resulted in an A1c of 8.6\%. ${ }^{14}$ It is unclear why the A1c of $8.6 \%$ was higher than predicted (7.8\%). The half-life of the RBC is 120 days so that at least one half-life (120 days or 17 weeks) would have been a better period of time to demonstrate benefit between fasting blood glucose and Alc (Table 1). Likewise, obtaining a FBG of $111 \mathrm{mg} / \mathrm{dl}$ after 13 weeks resulted in an average A1c of $7.8 \%$ and not $6.3 \%$ as might be predicted in Table $1 .{ }^{15}$ In a third study, 14 weeks of glargine resulted in a FBG of $132 \mathrm{mg} / \mathrm{dl}$ and an A1c of $8.0 \%$ where one might expect a $7.2 \%$ if the treatment period was at least 120 days. $^{12}$ The failure of the A1c to reflect the FBG is due to the 120 half-life of the glycosylated RBC which can delay an accurate A1c measurement.

Table I Relationship between FBG and AIC

\begin{tabular}{ll}
\hline Fasting glucose $(\mathbf{m g} / \mathbf{d l})$ & A lc $(\%)$ \\
\hline 100 & 6 \\
130 & 7 \\
160 & 8 \\
190 & 9 \\
220 & 10 \\
250 & 11 \\
280 & 12 \\
310 & 13 \\
340 & 14 \\
370 & 15 \\
400 & 16 \\
430 & 17 \\
460 & 18 \\
490 & 19 \\
\hline
\end{tabular}

In addition to the Table 1, this can be translated into a simple equation where $(\mathrm{FBG}+80) / 30=\mathrm{A} 1 \mathrm{c}$; for example, a $\mathrm{FBG}$ of 130 would be $(130+80) / 30=7.0 \%$; or a FBG of 190 would be $(190+80) / 30$ $=9 \%$. In these three studies, A1c measurements would have likely resulted in an lower A1c of approximately 6.7 for the first study, ${ }^{12}$ $7.6 \%$ for the second study ${ }^{14}$ and $6.3 \%$ for the third study, ${ }^{15}$ and $7.2 \%$ for the Davidson Study, ${ }^{12}$ respectively. The fact is that the FBG in DM-2 reflects the current glycemic goal but the A1c reflects that last 120-day average (3-4 month average) which lags behind the current improvement in control. In an attempt to validate the argument that for type 2 diabetics, the FBG is the best measurement to obtain better control was based on the observation that none of the studies of type 2 diabetic patients have demonstrated more than a $1.3 \%$ point decrease in A1c with prandial coverage. ${ }^{2-8}$ In the most recent study, the addition of 3 shots a day of Glulysine, the delta A $1 \mathrm{c}$ was $-0.4 \%$ reduced. ${ }^{12}$ While more patients were at goal, the risk for hypoglycemia was increased. An alternative approach may be obtained by drop-in the FBG by only 12 points (138 down to $126 \mathrm{mg} / \mathrm{dl})$ with the use of additional basal insulin as the 12 point drop would drop the $\mathrm{A} 1 \mathrm{c}$ by $0.4 \%$. Likewise in a second study, the addition of a single injection of glulisine resulted in an improvement of the A1c by $0.26 \% .^{15}$ Unfortunately, data interpretation is difficult with regards to this basal bolus study since the authors only used 12 weeks to obtain a FBG of 148 (estimated
Alc of 7.6\%) but the authors reported an Alc of $8.8 \%$. Based on fasting blood glucose concentration, the A1c would have been $7.6 \%$ if the authors maintained the basal injections for a sufficient period to allow the A1c to account for the 120 day half-life of A1c. In argument, approximately 2-3 half-lives would be required for one to be certain that the FBG is accurately reflected in A1c measurement. The addition of Aspart to basal insulin resulted in a drop of A1c to an average of $7.6 \%$. This was a $1.2 \%$ drop in A1c and could be considered a marked improvement in control. However, with the $1.2 \%$ drop in A1c was accompanied by a multifold increase in hypoglycemia. This is not to mention the additional costs for the rapid acting insulin and potential ER visits for severe hypoglycemia. Recent data suggests that intensive versus standard blood glucose control in North American type 2 diabetic patients increased all-cause mortality $(1.21, \mathrm{p}<0.05)$, CV mortality $(1.41, \mathrm{p}<0.05)$ and an associated OR of $3.52, \mathrm{P}<0.05)$ for severe hypoglycemia. ${ }^{16}$ Consistent with all the published clinical trial is the inability to obtain goal FBG. The push to fund research in prandial insulin from marker forces and the inability of the A1c to reach a steady state may have over inflated the apparent effectiveness of bolus insulin added to a basal regiment. Using basal insulin alone and obtaining a FBG of $148 \mathrm{mg} / \mathrm{dl}$ resulted after 12 weeks with only $4 \%$ of the population with an A1c concentration below 7\%. ${ }^{12}$ After 13 weeks with a final FBG of $111 \mathrm{mg} / \mathrm{dl}, 14 \%$ of the patients were below an A1c of $7 \% .{ }^{13}$ After 14 weeks, with a final FBG of $132 \mathrm{mg} / \mathrm{dl}, 36 \%$ of the patients had an A1c at or below 7.0\%. ${ }^{12}$ Most importantly, after six months with a final fasting blood glucose of $120 \mathrm{mg} / \mathrm{dl}, 46 \%$ of the patients had an A1c less than or equal to $7.0 \% .^{13}$

As shown in the regression equation, if a FBG of $90 \mathrm{mg} / \mathrm{dl}$ is obtained the $78 \%$ of patients on basal insulin alone should be at goal. Therefore, if one gets the FBG to $90 \mathrm{mg} / \mathrm{dl}$ within a 4-month period, then some $88 \%$ should be at goal. The average Alc after 6 months was $6.7 \%$ which is consistent with Table 1 estimate relationship between FBG and A1c. It is important to point out that approximately 17 weeks (4 months) is the minimal time (120 days) that is needed with a consistent FBG to see the effects of glycemia on A1c concentration. Asking the clinician to focus on FBG will simplify the goal for the patient, family and provider. Emphasis has been placed on the prandial insulin which has resulted in a delay in the advancement of insulin management seen in general internal medicine and family medicine clinics. If you make a goal simple for your patients and aim for fasting blood glucose of $90 \mathrm{mg} / \mathrm{dl}, 88 \%$ should obtain an A1c less than $7.0 \%$. This can be done easily by a single morning injection of basal insulin. The fault in many of the bolus studies is the failure to have a "basal only arm" once they were randomized to rapid insulin regimen and also not obtaining the stated fasting blood glucose goal. Not to point blame on much of the published data, but if one wanted to promote prandial insulin treatment, one could accept FBG in the higher range to allow the prandial insulin to show a greater benefit (larger area under the glucose excursion curve). This would also prevent hypoglycemia since you are starting at a glucose level of 130-140 with prandial injections and meals. Unfortunately, just because a study was not done and goals obtained should not provide reassurance in the obtained outcomes, poorly designed data should not drive medical care. The use of rapid insulins without continuing a placebo arm, ${ }^{12}$ having a very short lead in time,,$^{3-10,12-14}$ all contribute to the false impression that prandial insulin treatment in the type 2 diabetic is important. In fact, Buse et al., ${ }^{3}$ demonstrated that glargine treatment alone as compared to the use of BID (75/25 lispro protamine suspension/25\% lispro insulin) resulted in similar A1c concentration with one less 
injection per day. ${ }^{13}$ These authors keep the $\mathrm{FBG}$ at $120 \mathrm{mg} / \mathrm{dl}$ with glargine despite the fact that a small increase in glargine would have reduced the FBG to goal. Never-the-less, the additional drop in A1c based on the basal bolus insulin was $0.3 \%$. This same drop could have been obtained if the authors had obtained the drop of fasting blood glucose by $10 \mathrm{mg} / \mathrm{dl}$ (from $120-110 \mathrm{mg} / \mathrm{dl}$ ) as currently recommended by AACE guidelines. An entire 1\% drop in A1c would have been seen if the goal FBG of $90 \mathrm{mg} / \mathrm{dl}$ was obtained.

Only one study has targeted a FBG between $70-90 \mathrm{mg} / \mathrm{dl}$ and obtained a FBG of $79 \mathrm{mg} / \mathrm{dl}$. After 20 weeks, $64 \%$ obtained an A $1 \mathrm{c}<7 \%$. In those who obtained a FBG between 70 and $110,54 \%$ obtained an A1c $<7 \% .{ }^{17}$ Average A1c was $6.7 \%$ in the $70-90 \mathrm{mg} /$ $\mathrm{dl}$ arm and $7.0 \%$ in the $70-110 \mathrm{mg} / \mathrm{dl}$ arm. As in most other studies, the goal FBG was not obtained and the mean FBG at the end of the study were $106 \mathrm{mg} / \mathrm{dl}$ and $111 \mathrm{mg} / \mathrm{dl}$. If the authors were to obtain a mean FBG goal of $80 \mathrm{mg}$ in the intense arm, then the A1c would have been approximately $0.9 \%$ better than reported. In addition, the short term 12- week period of a good FBG was not been long enough to complete the 120 day duration for A1c steady state. Figure 1 reflects the actual relationship between final FBG and A1c as well as the predicted A1c based on FBG obtained (if adequate time i.e. 120 days) had elapsed at that FBG (Figure 1). Lastly, recent studies have shown that small changes in FGB results in significant difference as earlier studies. ${ }^{12-15,17-19,26}$ Our hypothesis that $70 \%$ s of the patients would be at ADA goal A1c $\leq 7.0 \%$ if the FBG of 90 was obtained is supported by the data in Figure 1. This figure is an underestimate of the real number at goal based on the fact that most studied did not sustain FBG for a 4 month period prior (RBC life span) to measurement of A1c level. Using the newer ACP guideline A1c goal $<8.0 \%$ then Figure 1 shows that some $90 \%$ can be at goal if the FBG is 120 . This is consistent with the new ADA guidelines that basal insulin should used to obtain a target FBG for several months. After several months, and I would suggest 4 to 6 months, then measure the A1c to see if at A1c goal.

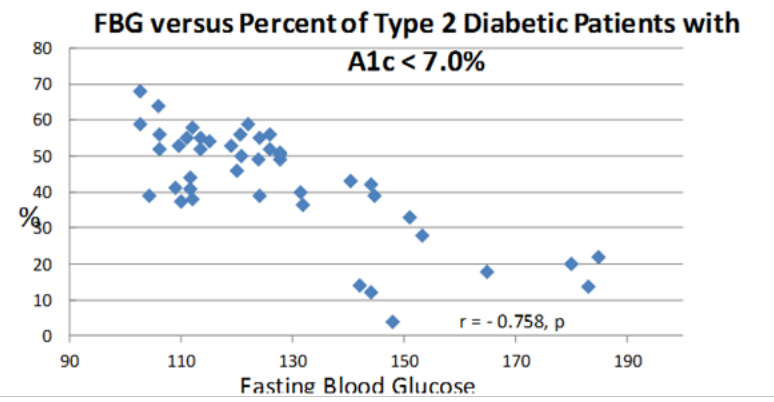

Figure I FGB versus Percent of type 2 diabetic patients with $\mathrm{Al}$ c $<7.0 \%$

\section{Conclusion}

Basal insulin is a safe and easy way to obtain goal A1c withou the risk of severe hypoglycemia. A goal of FBG of 110 should be obtained initially for 2-months to avoid excessive beta cell recover and subsequent hypoglycemic. After 2-3 months the target FBG could be lowered to $90 \mathrm{mg} / \mathrm{dl}$ with sufficient time elapsed to measure the A1c. ADA recommends measurement of Alc every 3 months when the patient is not at goal. It important to point out that the A1c takes 120 days (approximately 4 months) to get to a new steady state. Checking A1c every 3 months may be too soon to evaluate the effect of basal insulin if the FBG has not been at goal for 2-3 months. Using the simple formulates to estimate control may be helpful: $(\mathrm{FBG}+80) / 30$ to estimate A1c. Patience is a virtue when treating patients with type
2 diabetes who are on insulin. Clinicians should focus of fasting glucose concentration with medical visits and not evaluate the Alc, as sufficient time may has not elapsed to see ones goal A1c. With the new recommendation by ACP to obtain an A1c between 7.0 to $7.9 \%$ the ability to obtain this should be easier as one can still target a FBG of 130 and get your patient to goal. ADA 2018). Simplifying the goal of treatment in diabetes to FBG provides the patient with more selfcontrol at obtaining this goal and gives them an easy home monitor to keep a check on their diabetes. The target of FBG in type 2 diabetics should improve compliance, reduced costs associated hypoglycemia, use of expensive prandial insulin and cost associated with frequent glucose monitoring at home.

\section{Funding Availability}

The NIH Clinical Investigator Award KO8DK02083 and MO1RR-00425 supported this grant.

\section{Acknowledgments}

Thanks for Sajad Hamal, MS, CCRP for his editing of the manuscript.

\section{Conflicts of interest}

Author declares there is no conflict of interest.

\section{References}

1. Aschner P, Chan J, Owens DR, et al. Insulin glargine versus sitagliptin in insulin-naïve patients with type 2 diabetes mellitus uncontrolled on metformin (EASIE): a multicenter, randomized open-label trial. Lancet 2012;379(9833):2262-2269.

2. Lund S, Vaag A. Insulin initiation in patients with type 2 diabetes mellitus: treatment guidelines, clinical evidence and patterns of use of basal vs premixed insulin analogues. Eur J Endocrinol. 2012;166(2):159-170.

3. Buse JB, Wolffenbuttel BH, Herman WH, et al. DURAbility of basal versus lispro mix 75/25 insulin efficacy (DURABLE) trial 24-week results: safety and efficacy of insulin lispro mix 75/25 versus insulin glargine added to oral antihyperglycemic drugs in patients with type 2 diabetes. Diabetes Care. 2009;32(6):1007-1013.

4. Holman RR, Thorne KI, Farmer AJ, et al. Addition of biphasic, prandial, or basal insulin to oral therapy in type 2 diabetes. $N$ Engl $\mathrm{J} \mathrm{Med}$. 2007;357:1716-1730.

5. Jacober SJ, Scism-Bacon JL, Zagar AJ. A comparison of intensive mixture therapy with basal insulin therapy in insulin-naive patients with type 2 diabetes receiving oral anti-diabetes agents. Diabetes Obes Metab. 2006;8(4):448-455.

6. Kann PH, Wascher T, Zackova V, et al. Starting insulin therapy in type 2 diabetes: twice-daily biphasic insulin Aspart 30 plus metformin versus once-daily insulin glargine plus glimepiride. Exp Clin Endocrinol Diabetes. 2006;114(9):527-532.

7. Kazda C, Hulstrunk H, Helsberg K, et al. Prandial insulin substitution with insulin lispro or insulin lispro mid mixture vs. basal therapy with insulin glargine: a randomized controlled trial in patients with type 2 diabetes beginning insulin therapy. J Diabetes Complications.2006;20(3):145-152.

8. Malone JK, Kerr LF, Campaigne BN, et al. Combined therapy with insulin lispro Mix 75/25 plus metformin or insulin glargine plus metformin: a 16-week, randomized, open-label, crossover study in patients with type 2 diabetes beginning insulin therapy. Clin Ther. 2004;26(12):2034-2044.

9. Raskin P, Allen E, Hollander P, et al. Initiating insulin therapy in type 2 Diabetes: a comparison of biphasic and basal insulin analogs. Diabetes Care. 2005;28(2):260-265 
10. Strojek K, Bebakar WM, Khutsoane DT, et al. Once daily initiation with biphasic insulin aspart 30 versus insulin glargine in patients with type 2 diabetes inadequately controlled with oral drugs: an open-label, multinational RCT. Curr Med Res Opin. 2009;25(12):2887-2894.

11. Brunzell JD, Robertson RP, Lemer RL, et al: Relationship between fasting plasma glucose levels and insulin secretion during intravenous glucose tolerance tests. J Clin Endocriol Metab. 1976;42(2):222-229.

12. Davidson M, Raskin B, Tanenberg RJ, et al. A stepwise approach to insulin therapy in patients with type 2 diabetes mellitus and basal insulin treatment failure. Endocr Pract. 2011;17(3):395-403.

13. Buse JB, Wolffenbuttel BH, Herman WH, et al. The DURAbility of Basal versus Lispro mix $72 / 25$ insulin Efficacy (DURABLE) trial: comparing the durability of lispro mix $72 / 25$ and glargine. Diabetes Care. 2011;34(2):249-255.

14. Meneghini L, Mersebach H, Kumary S, et al. Comparison of 2 intensification regiments with rapid-acting insulin aspart in type 2 diabetes mellitus inadequately controlled by once-daily insulin determir and oral antidiabetic durgs: the step-wise randomized study. Endocr Pract. 2011;17(5):727-736

15. Owens DR, Luzio SD, Sert-Langeron C, et al. Effects of initiation and titration of a single pre-prandial dose of insulin glulisine while continuing titrated insulin glargine in type 2 diabetes: a 6-month 'proof-of-concept' study. Diabetes Obes Metab. 2011;13(11):1020-1027.

16. Sardar P, Udell JA, Chatterjee S, et al. Effect of intensive versus standard blood glucose control in patients with type 2 diabetes mellitus in different regions of the world: Systemic review and meta-analysis of randomized controlled trials. J Amer Heart Asoc. 2015; 4(5):e001577.

17. Blonde L, Merilainen M, Karwe V, et al. Patient-directed titration for achieving glycemic goals using a once-daily basal insulin analogue: an assessment of two different fasting plasma glucose targets-the TITRATE study. DM, Obesity and Met. 2009;11(6):623-631.

18. Meneghini L, Kesavadev J, Demissie M, et al. Once-daily initiation of basal insulin as add-on to metformin: a 26-week, randomized, treat-totarget trial comparing insulin detemir with insulin glargine in patients with type 2 diabetes. DM, Obesity and Met. 2013;15(8):729-736.
19. Blonde L, Jendle J, Gross J, et al. Once-weekly dulaglutide versus bedtime insulin glargine, both in combination with prandial insulin lispro, in patients with type 2 diabetes (AWARD-4): a randomized, open-label, phase 3,non-inferiority study. Lancet. 2015;385(9982):2057-2066

20. Yki-Jarvinen H, Kauppila M, Kujansuu E, et al. Comparison of insulin regimens with non-insulin dependent diabetes mellitus. NEJM. 1992;327(20):1426-1433.

21. Qaseem A, Wilt TJ, Kansagara D, et al. Hemoglobin A1c targets for glycemic control with pharmacologic therapy for nonpregnant adults with type 2 diabetes mellitus: a guidance statement update from the American College of Physicians. Annals Int Med. 2018;168(8):569-576.

22. Wysham C, Bhargava A, Chykin L, et al. Effect of insulin degludec vs insulin glargine U100 on hypoglycemia in patients with type 2 diabetes: The SWITCH 2 randomized clinical trial. JAMA. 2017:18(1);45-56.

23. Cefalu WT, Leiter LA, de Bruin TW, et al. Dapaglifozin's effect on glycemia and cardiovascular risk factors in high-risk patients with type 2 diabetes: A 24-week, multicenter, randomized, double-blind, placebocontrolled study with a 28-week extension. DM Care. 2015;38(7):18-27.

24. Home P, Shankar RR, Gantz I, et al. A randomized, double-blind trial evaluating the efficiency and safety of monotherapy with the once-weekly dipeptidyl peptidase-4 inhibitor omarigliptin in people with type 2 diabetes. DM Res and Clin Prac. 2018;138:253-261.

25. Davies M, Pieber TR, Hartoft-Nielsen ML, et al. Effect of oral semaglutide compared with placebo and subcutaneous semaglutide on glycemic control in patients with type 2 diabetes: A randomized clinical trial. JAMA. 2017;318(15):1460-1470.

26. Vanderheiden A,Harrison L, Warshauer J, et al. Effect of adding liraglutide vs placebo to a high-dose insulin regiment in patients with type 2 diabetes; A randomized clinical trial. JAMA Int Med. 2016;176(7):939-947. 